\title{
The effect of skin temperature on vibratory sensitivity in polyneuropathy
}

\author{
RICHARD TEGNÉR \\ From the Department of Neurology, Karolinska Hospital, Stockholm, Sweden
}

SUMMARY In normal subjects, a rise in skin temperature causes a decrease in vibratory perception thresholds. In this study, vibratory thresholds on the foot were measured before and after local warming of the skin in patients with diabetic or uraemic neuropathy. On warming, the thresholds increased in nine of 11 diabetic patients while they decreased in 10 of 13 uraemic patients. In two-thirds of the patients, the response was outside the range of normal short term variation.

This study is based on two observations. First, vibratory perception thresholds decrease if the skin is warmed. ${ }^{2}$ Second, demyelinated nerve fibres are sensitive to small rises in temperature. ${ }^{3}$ An increase of only $0.5^{\circ} \mathrm{C}$ can block conduction in a demyelinated internode. ${ }^{4}$ The present investigation was undertaken to test the hypothesis that demyelinating peripheral diseases cause an abnormal response to skin warming, that is an increase in vibratory thresholds. The vibratory sensitivity was tested in 11 patients with diabetic neuropathy, which is, in part, a demyelinating neuropathy. ${ }^{56}$ For comparison, measurements were also made in 13 patients with uraemic neuropathy, which is an axonal neuropathy. ${ }^{7}$

\section{Patients and methods}

The diabetic group comprised three women and eight men with a mean age of 46 years (range 33-66 years). They all had type 1 diabetes mellitus with a duration of 18 to 46 years. The uraemic group comprised six women and seven men with a mean age of 53 years (range 37-71 years). The diagnoses were chronic glomerulonephritis (6), chronic pyelonephritis (4), and polycystic kidney disease (3). They were treated with continuous ambulatory peritoneal dialysis (6) or haemodialysis (7). All patients had a creatinine clearance rate less than $5 \mathrm{ml} / \mathrm{min}$.

Vibratory thresholds were determined with a handheld vibrameter (Somedic $A B$ ), where the movement of the stimulating probe (diameter $13 \mathrm{~mm}$ ) was recorded continously by means of an accelerometer. The movement amp-

Address for reprint requests: Richard Tegnér, Department of Neurology, Karolinska Hospital, Box 60 500, S-104 01. Sweden.

Received 12 June 1984. Accepted 14 July 1984 litude was displayed digitally in $\mu \mathrm{m}$ and the perception thresholds were determined by the method of limits. ${ }^{9}$ Measurements were made, on each side, dorsomedially on the first metatarsal bone. For details of the technique, see Goldberg and Lindblom. ${ }^{10}$ Their normal material was used for age corrections. After base line recordings, the side with the less variability was chosen to study the influence of temperature. The foot and the lower leg were warmed by $a$ heating lamp. Measurements were made after approximately five minutes when the skin temperature at the recording site was $36-37^{\circ} \mathrm{C}$. This corresponds to a mean increase of $6.3^{\circ} \pm 1 \cdot 2^{\circ} \mathrm{C}$. All recordings were made by examiners who were unaware of the purpose of the invese tigation.

The short term variability of the vibratory thresholds was examined in 20 consecutive patients with polyneuropathies of varying aetiology. The procedure was as above but the skin was not warmed. Nerve conduction velocities were measured in the median, the peroneal, and the sural nerve. All measurements were performed at the Department of Clinical Neurophysiology, Karolinska Hospital. Standard techniques for surface electrodes were used. Corrections for age and skin temperature were done according to Ludin."

Wilcoxon's rank sum test and Fisher's exact test for four-fold tables were used for the statistical analyses. When possible, values are expressed as mean \pm SD.

\section{Results}

All diabetic patients had clinical signs of neuropathy as well as decreased nerve conduction velocity in at least one of the three nerves tested. In the uraemic group, one patient had no clinical or neurographic signs, otherwise findings were similar to the diabetic group. Vibratory thresholds, prior to warming, were abnormal in six of the 11 diabetic patients and in eight of the 13 uraemic patients. 


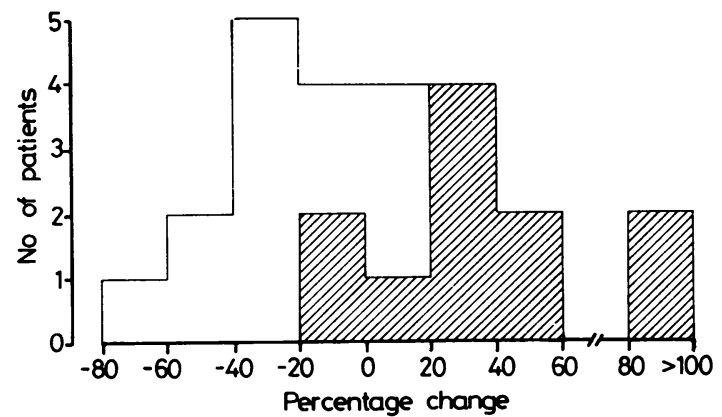

Fig Vibratory perception thresholds were measured on the foot before and after warming of the skin. Percent changes in diabetic (hatched squares) and in uraemic patients (unfilled squares).

When the skin temperature was increased from the normal range of $28-32^{\circ} \mathrm{C}$ to $36-37^{\circ} \mathrm{C}$, vibratory thresholds increased in nine of the 11 diabetic patients and decreased in 10 of the 13 uraemic patients $(p=0.006)$, see figure. The mean change was $+49.7 \pm 59.8 \%$ in the diabetic group and $24.2 \pm 23.5 \%$ in the uraemic group $(\mathrm{p}<0.001)$.

In the control group of 20 patients, short term changes ranged from 0 to $17 \%$ with the mean of the absolute values being $7 \cdot 8 \pm 6 \cdot 2 \%$. This accords with previous studies. ${ }^{1012}$ A $95 \%$ confidence interval then gives the following distribution: no significant effect of warming in $1 / 3$ of the patients; a significant increase in $1 / 3$, all diabetics; and a significant decrease in $1 / 3$, all uraemics.

The effect of warming could not be related to (1) the degree of renal impairment, (2) the duration of diabetes, (3) the type of dialysis treatment, (4) the nerve conduction velocities, nor (5) the vibratory thresholds prior to warming.

\section{Discussion}

Previous studies have shown that vibratory perception thresholds decrease after a rise in skin temperature. ${ }^{2}$ The response depends on the stimulus frequency, ${ }^{213}$ and it is probably also influenced by the size of the stimulating probe, the stimulus-site location, the use of a rigid annulus around the stimulating probe,$^{13}$ and the size of the area that is warmed. The major finding of this study was that, on warming the skin, the vibratory thresholds increased in the diabetic patients and decreased in the uraemic patients.

Axonal degeneration is the most common abnormality in nerve biopsies from uraemic patients. ${ }^{78}$ In diabetics, on the other hand, there is both axonal loss and primary segmental demyelination. ${ }^{56}$ It is possible that the remaining nerve fibres in uraemic neuropathy respond normally to warming. In contrast, demyelinated nerve fibres may contribute to the vibratory perception at normal temperatures, but when the nerve is warmed, conduction is blocked in these fibres and the vibratory threshold increases.

An alternative explanation could involve the normal response of vibratory thresholds on warming. The cause of this phenomenon is unknown. It is probably not related to an increased local blood flow or an altered skin conductivity. ${ }^{1}$ An investigation by Inman and Peruzi ${ }^{14}$ may be relevant. In recordings from isolated Pacinian corpuscles, they observed repetitive firing after a single stimulus at temperatures above $31 \cdot 5^{\circ} \mathrm{C}$. Their explanation was that at room temperature, the durations of the receptor potential and the nerve action potential are about equal. This means that the first node is refractory during the entire course of the receptor potential. As the temperature is raised, the refractory period of the axon decreases, while the duration of the receptor potential remains constant. At a certain temperature, the refractory period will be sufficiently short to allow re-excitation. Close to the vibratory perception threshold, the nerve fibres are still not entrained. ${ }^{15}$ This means that warming could increase the number of impulses transmitted centrally, which would increase the probability of detection. The refractory period is prolonged in both uraemic $^{16}$ and in diabetic ${ }^{17}$ patients. The underlying mechanisms are unknown and may well differ in their temperature sensitivity. Note that this explanation requires that the warmth has penetrated sufficiently deep to influence the Pacinian corpuscles and the initial segments of the axons. Since the exact location of the Pacinian corpuscles is unknown, the temperature at the receptor site can not be measured.

There was a substantial overlap between the two groups, which at present makes the method less useful clinically. It is possible that a better separation can be obtained by changing the size of the stimulating probe, by varying the stimulus frequency, or by warming the whole leg.

This work was supported by the Foundations of the Karolinska Institute and by the Vivian L. Smith Foundation for Restorative Neurology. I thank Ulf Lindblom and Christopher Korch for carefully reading the manuscript.

\section{References}

1 Weitz J. Vibratory sensitivity as a function of skin temperature. J Exp Psychol 1941;28:21-36. 
${ }^{2}$ Green BG. The effect of skin temperature on vibrotactile sensitivity. Perception and Psychophysics 1977;21:243-8.

${ }^{3}$ Davis FA, Jacobson S. Altered thermal sensitivity in injured and demyelinated nerve. $J$ Neurol Neurosurg Psychiatry 1971;34:551-61.

${ }^{4}$ Rasminsky M. The effects of temperature on conduction in demyelinated single nerve fibers. Arch Neurol 1973;28:287-92.

${ }^{s}$ Thomas PK, Lascelles RG. The pathology of diabetic neuropathy. $Q J$ Med 1966;35:489-509.

- Sugimura K, Dyck PJ. Sural nerve myelin thickness and axis cylinder caliber in human diabetes. Neurology (Ny) 1981;31:1087-91.

? Dyck PJ, Johnson WJ, Lambert EH, O’Brien PC. Segmental demyelination secondary to axonal degeneration in uremic neuropathy. Mayo Clin Proc 1971;46:400-31.

* Thomas PK, Hollinrake K, Lascelles RG, et al. The polyneuropathy of chronic renal failure. Brain 1971;94:761-80.

${ }^{9}$ Gescheider GA. Psychophysics. Method and Theory. Hillsdale, New Jersey: Lawrence Erlbaum Associates, 1976.

${ }^{10}$ Goldberg JM, Lindblom U. Standardised method of determining vibratory perception thresholds for diagnosis and screening in neurological investigations. $J$
Neurol Neurosurg Psychiatry 1979;42:793-803.

"Ludin H-P. Electromyography in Practice. Stuttgart, New York: Georg Thieme Verlag, 1981.

12 Fagius J, Wahren L-K. Variability of sensory threshold determinations in clinical use. $J$ Neurol Sci 1981;51:11-27.

${ }^{13}$ Bolanowski SJ, Verrillo RT. Temperature and criterion effects in a somatosensory subsystem: a neurophysiological and psychophysical study. $J$ Neurophysiol 1982;48:836-55.

${ }^{14}$ Inman DR, Peruzzi P. The effects of temperature on the responses of Pacinian corpuscles. J Physiol (London) 1961;155:280-301.

is Talbot WH, Darian-Smith I, Kornhuber HH, Mountcastle VB. The sense of flutter-vibration: comparison of the human capacity with the response patterns of mechanoreceptive afferents from the monkey hand. $J$ Neurophysiol 1968;31:301-34.

${ }^{16}$ Lowitzsch K, Göhring U, Hecking E, Köhler H. Refractory period, sensory conduction velocity and visual evoked potentials before and after haemodialysis. $J$ Neurol Neurosurg Psychiatry 1981;44:121-8.

17 Tackmann W, Ullerich D, Lehmann HJ. Impulse series neurography and paired stimuli in early stages of human polyneuropathy. In: Kunze K, Desmedt JE, eds. Studies on Neuromuscular Diseases. Basel: S Karger, 1975:251-7. 